\title{
Effect of the application time of phosphoric acid and self-etch adhesive systems to sclerotic dentin
}

\begin{abstract}
Alexandra Patricia MENA-SERRANO ${ }^{1}$, Eugenio Jose GARCIA², Miguel Muñoz PEREZ ${ }^{3}$, Gislaine Cristine MARTINS 4 , Rosa Helena Miranda GRANDE ${ }^{5}$, Alessandro Dourado LOGUERCIO ${ }^{6}$, Alessandra REIS ${ }^{7}$
\end{abstract}

\footnotetext{
1- DDS, MSc, PhD student, School of Dentistry, Department of Restorative Dentistry, State University of Ponta Grossa, Ponta Grossa, PR, Brazil.

2- Visiting Professor, School of Dentistry, University of São Paulo, São Paulo, SP, Brazil.

3- DDS, MSc, PhD student, School of Dentistry, Department of Restorative Dentistry, State University of Ponta Grossa, Ponta Grossa, PR, Brazil. Adjunctive Professor, University of Valparaíso, Valparaíso, Chile.

4- DDS, MSc, PhD, Visiting Professor of ABOPG, Ponta Grossa, PR, Brazil.

5- DDS, MSc, PhD, Associate Professor, School of Dentistry, Department of Dental Materials, University of São Paulo, São Paulo, SP, Brazil.

6- DDS, MSc, PhD, Adjunctive Professor, School of Dentistry, Department of Restorative Dentistry, State University of Ponta Grossa, Ponta Grossa, PR, Brazil.

7- DDS, MSc, Adjunctive Professor, School of Dentistry, Department of Restorative Dentistry, State University of Ponta Grossa, Ponta Grossa, PR, Brazil.
}

Corresponding address: Profa. Dra. Alessandra Reis - Universidade Estadual de Ponta Grossa - Mestrado em Odontologia - Rua Carlos Cavalcanti, 4748

- Bloco M - Sala 64A - Uvaranas - 84030-900. Ponta Grossa - PR - Brasil - e-mail: reis_ale@hotmail.com

Received: February 14, 2012 - Modification: February 6, 2013 - Accepted: February 9, 2013

\section{ABSTRACT}

$\mathrm{O}$

bjectives: To evaluate the effect of application time on the resin-dentin bond strength ( $\mu$ TBS) and etching pattern of adhesive systems applied on sclerotic dentine. Material and Methods: A total of forty-two bovine incisors had their roots removed. The 1-step self-etch GO (SDI), the 2-step self-etch Adper SE Bond (3MESPE) and the 35\% phosphoric acid (3MESPE) from the 2-step etch-and-rinse Adper Single Bond 2 (3MESPE) were applied on the bovine incisal surfaces according to the manufacturer's instructions or duplicating the recommended conditioning time. After adhesive application, thirty teeth were restored with composite resin, stored for $24 \mathrm{~h}$ in distilled water at $37^{\circ} \mathrm{C}$, and sectioned into resindentin bonded sticks $\left(0.8 \mathrm{~mm}^{2}\right)$ and tested according to the $\mu$ TBS at $0.5 \mathrm{~mm} / \mathrm{min}$. The etching pattern of the remaining twelve teeth $(n=4$ for each material) was examined under scanning electron microscopy. Each tooth was divided into a buccal-to-lingual direction into three thirds, and each third randomly assigned to the groups: control (no treatment), according to the manufacturers' instructions and duplicating the recommended application time. The $\mu$ TBS and the relative percentage of the tubule area opening were evaluated by two-way repeated measures ANOVA and Tukey's tests $(\alpha=0.05)$. Results: The duplication of the conditioning time favored only the GO adhesive $(p<0.05)$. Both application methods significantly increased the tubule area opening $(p<0.05)$ compared to the controls. Conclusions: The efficacy of duplicating the conditioning time was only effective for the 1 -step self-etch adhesive system tested.

Key words: Dentin. Acid etching, Dental. Dentin-bonding agents.

\section{INTRODUCTION}

The primary goal of dentin bonding systems is to provide retention of restorative materials to the dental structure as well as to seal the dentin substrate. Even though the immediate bonding effectiveness of most current adhesive systems is favorable ${ }^{6}$, these findings are based upon their ability to bond sound dentin. Although sound dentin may be a common substrate in the daily practice, a variety of pathological dentin substrates are also encountered in clinical scenarios, which includes carious-affected and sclerotic dentin ${ }^{7,26}$. Irrespective of the bonding strategy used, bonding to pathologically altered substrates such as sclerotic dentin led to compromised bonding ${ }^{17,26}$. This has been due to partial or complete obliteration of the dentinal tubules with mineral crystals and due to the presence of an acid-resistant hypermineralized layer that acts as an acid resistant substrate ${ }^{17,26}$.

As the current bonding strategies [etch-and- 
rinse (ER) and self-etch (SE) adhesives] rely primarily on micromechanical retention, the existence of such obstacles may compromise effective infiltration of resin monomers into the dental tissues. Thus, previous studies suggested that bonding to human sclerotic dentin could be improved by changing the adhesive protocol that is typically employed for sound dentin. For ER systems, the duplication of the phosphoric acid conditioning time was suggested; however, the effectiveness of this approach is not unanimous ${ }^{4,18,19}$. As for the SE adhesives, phosphoric acid pre-treatment ${ }^{8,16}$ or surface roughening of the sclerotic dentin with diamond burs ${ }^{8,27}$, has also been suggested. To the extent of the author's knowledge, no study has so far evaluated the effectiveness of duplication of the conditioning time of SE in sclerotic dentin.

Although phosphoric acid conditioning or surface roughening of sclerotic dentin has shown promising results, they increase the number of clinical steps or may produce thicker smear layers when diamond burs are employed. Thicker smear layers were shown to restrict the penetration of some SE adhesives into the dentin ${ }^{16,25}$. Therefore, other simpler strategies should be investigated. Thus, the aim of this study was to evaluate the micro-tensile resin-dentin bond strength ( $\mu$ TBS) and etching pattern of ER and SE adhesives to sclerotic bovine dentin applied as recommended by the manufacturers or after duplicating the conditioning time. The null hypothesis tested was that bonding to sclerotic dentin will not be affected by the application time of the ER and SE adhesives.

\section{MATERIAL AND METHODS}

The Ethics Committee from the State University of Ponta Grossa (Paraná, Brazil) reviewed and approved this study under protocol number 06289/09. Forty-two bovine incisors, from animals older than 3 years old ${ }^{2}$ were obtained from a local slaughterhouse. These teeth exhibit natural dentin exposure in the incisal edges, and therefore, no bur preparation was required to expose the dentin substrate for bonding.

The roots were sectioned with a water-cooled low-speed diamond saw (Isomet 1000, Buehler, Lake Bluff, IL, USA). The coronal pulp was removed and the pulp chamber was kept unfilled. The smear-layer free incisal surfaces were cleaned with an anionic detergent rubbed with a disposable sponge for $30 \mathrm{~s}$ and rinsed in running water for $30 \mathrm{~s}$.

For the $\mu$ TBS testing, thirty teeth were randomly selected and divided into six groups according to the combination of the main factors Adhesive ( 3 levels) and Application time (2 levels) so that 5 teeth were employed in each group.
Before the adhesive application, one third of each crown was longitudinally sectioned in a buccal-to-lingual direction using a water-cooled low-speed diamond saw (Isomet 1000) in order to ensure that the bonding substrate was, in fact, sclerotic (Figure 1). In these thirds, no treatment was performed, and the specimens were mounted on aluminum stubs and desiccated in colloidal silica for $24 \mathrm{~h}$. After this period, they were goldsputtered (Sputter Coater IC 50, Shimadzu, Tokyo, Japan) and examined under the scanning electron microscope (SEM). The SEM was operated in the secondary electrons mode (SSX-500, Shimadzu, Tokyo, Japan) with an accelerating voltage of 12 $\mathrm{kV}$. In case the sclerotic characteristic was not confirmed, the specimen was discarded.

In the other two thirds (not sectioned), the 1-step SE GO (GO, SDI, Bayswater, Victoria, AU), the 2-step SE Adper SE Bond (ASE, 3MESPE, St. Paul, MN, USA), and the 2-step ER Adper Single Bond 2 (SB2, 3MESPE, St. Paul, MN, USA) were applied according to the manufacturers' instructions or duplicating the conditioning time (Figure 2). A total of 5 tooth specimens were employed for each group. The application mode, composition and batch number of the adhesive systems are shown in Figure 2.

The adhesives were applied by a single and calibrated operator (Figure 2). Composite resin build-ups (Opallis, FGM, Joinville, SC, Brazil) were constructed in three increments of $1 \mathrm{~mm}$, and each one was light-cured for $40 \mathrm{~s}$ (Figure 1). The lightcuring unit was set at $500 \mathrm{~mW} / \mathrm{cm}^{2}$ (VIP, Bisco, Schaumburg, IL, USA) and used throughout the restorative procedure.

After $24 \mathrm{~h}$ of storage in distilled water at $37^{\circ} \mathrm{C}$, the specimens were longitudinally sectioned in both " $x$ " and " $y$ " directions by means of a watercooled low-speed diamond saw (Isomet 1000, Buehler) in order to obtain approximately 10-14 resin-dentin bonded sticks per tooth, with a crosssectional area of approximately $0.8 \mathrm{~mm}^{2}$ (Figure 1). All the resin-dentin bonded sticks were tested in a universal testing machine at a crosshead speed

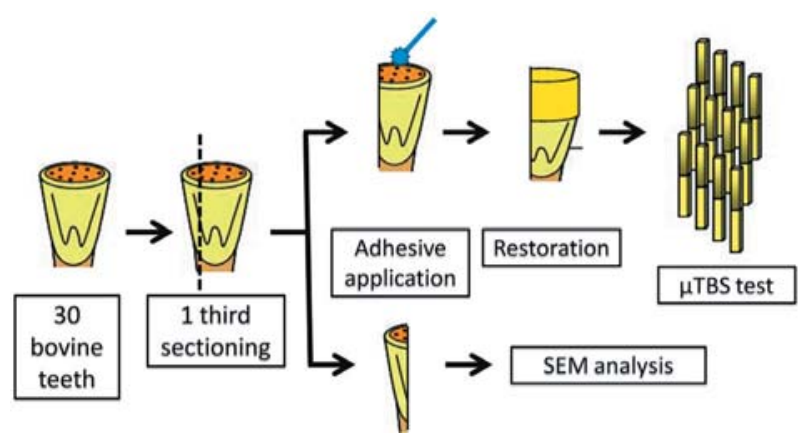

Figure 1- Flowchart of the micro-tensile bond strength ( $\mu$ TBS) test 
of $0.5 \mathrm{~mm} / \mathrm{min}$ (Kratos, São Paulo, SP, Brazil). The fracture mode was analyzed at $40 \mathrm{X}$ magnification and classified as (1) cohesive within dentin; (2) cohesive within composite resin and (3) adhesive or adhesive/mixed (failure at the resin/dentin interface or mixed with cohesive failure of the neighboring substrates). The number of specimens with premature failures during the specimen preparation was also recorded.

For the etching pattern analysis, the remaining twelve teeth were divided into three groups ( $n=4$ teeth per group) according to the material to be used (Figure 2). The crowns of these twelve bovine teeth were longitudinally sectioned in a buccal-to-lingual direction with a water-cooled low-speed diamond saw (Isomet 1000), in order to obtain three crown thirds. One third was used for the evaluation of the sclerotic dentin degree, where no treatment was performed; the second third was treated with one of the adhesives applied according to the manufacturers' instructions and the last third was treated with the same material but duplicating the conditioning time (Figure 3). The allocation of each third to the subgroup was randomly determined.

In the SE groups, the adhesives were applied as described earlier for the $\mu$ TBS testing, but they were not light-cured. Then, the resin monomers of the self-etch primer were removed by immediately immersing the specimens in acetone for $5 \mathrm{~min}$ followed by immersion in deionized water for 5 min. After this, the specimens were immersed in $96 \%$ ethanol for $5 \mathrm{~min}$ and again in deionized water for $5 \mathrm{~min}^{13}$. The specimens treated with phosphoric acid were only rinsed with deionized water for 15 s (Figure 3).

They were mounted on aluminum stubs, ultrasonically cleaned with distilled water for 30 min (Dabi Atlante, Ribeirão Preto, SP, Brazil) and desiccated in colloidal silica for $24 \mathrm{~h}$. After this period, they were gold-sputtered (Sputter Coater IC 50, Shimadzu) and examined under the scanning electron microscope (SEM). The SEM was operated in the secondary electrons mode (SSX500 , Shimadzu) with an accelerating voltage of $12 \mathrm{kV}$ (Figure 3).

Three pictures were taken of each crown third. The relative percentage of the tubule area occlusion of each specimen was measured in all pictures using the UTHSCSA ImageTool 3.0 software (Department of Dental Diagnostic Science at The University of Texas Health Science Center, San Antonio, Texas, USA) by a blinded author.

The $\mu$ TBS values of sticks from the same tooth half were averaged. Specimens with a cohesive fracture mode and premature failures were excluded from the tooth half mean. The three readings of the relative open tubule area from the same tooth half were averaged for statistical purposes. Data from the $\mu$ TBS testing and the relative percentage of the open tubule area were evaluated by two-way repeated measures ANOVA

\begin{tabular}{|c|c|c|}
\hline Material & Composition (batch number) & Application mode \\
\hline $\begin{array}{l}\text { Adper Single } \\
\text { Bond } 2\end{array}$ & $\begin{array}{c}\text { Etchant: } 35 \% \text { phosphoric acid }(997505) \\
\text { Adhesive: dimethacrylates, HEMA, polyalkenoid } \\
\text { acid copolymer, } 5 \mathrm{~nm} \text { silane treated colloidal silica, } \\
\text { ethanol, water, photoinitiator ( } 7 \mathrm{NK} \text { ) }\end{array}$ & $\begin{array}{l}\text { 1. Apply Scotchbond }{ }^{\mathrm{TM}} \text { Etchant to dentin for } \\
15 \mathrm{~s} \text { (control group) or for } 30 \mathrm{~s} \text { (experimental } \\
\text { group) } \\
\text { 2. Rinse for } 10 \mathrm{~s} \text {. } \\
\text { 3. Blot excess water. } \\
\text { 4. Apply 2-3 consecutive coats of adhesive for } \\
15 \mathrm{~s} \text { with gentle agitation. } \\
\text { 5. Gently air thin for } 5 \mathrm{~s} \text {. } \\
\text { 6. Light-cure for } 10 \mathrm{~s} \text {. }\end{array}$ \\
\hline $\begin{array}{c}\text { Adper } \\
\text { Scotchbond SE }\end{array}$ & 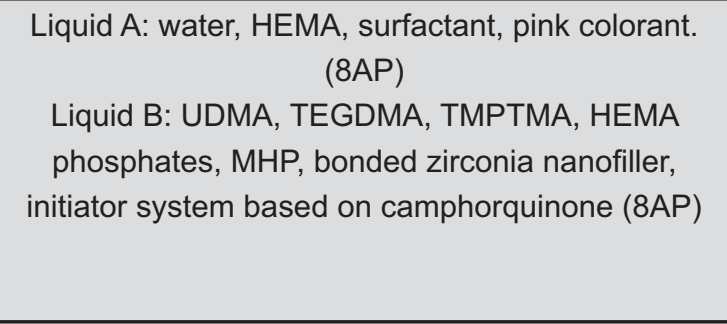 & $\begin{array}{l}\text { 1. Apply Liquid } \mathrm{A} \text { to the entire bonding area. } \\
\text { 2. Apply Liquid } \mathrm{B} \text { scrubbing, for } 20 \mathrm{~s} \text { (control } \\
\text { group) or for } 40 \mathrm{~s} \text { (experimental group) } \\
\text { 3. Air dry for } 10 \mathrm{~s} \text {. } \\
\text { 4. Apply a second coat of Liquid B. } \\
\text { 5. Lightly air thin the adhesive layer. } \\
\text { 5. Light cure for } 10 \mathrm{~s} \text {. }\end{array}$ \\
\hline GO & $\begin{array}{c}\text { Phosphoric acid ester monomer, dimethacrylate } \\
\text { monomer, monomethacrylate monomer, silicon } \\
\text { dioxide filler, water, acetone, photoinitiators, } \\
\text { stabilizer, sodium (071001) }\end{array}$ & $\begin{array}{l}\text { 1. Apply and leave in place for } 20 \mathrm{~s} \text { (control } \\
\text { group) or } 40 \mathrm{~s} \text { (experimental group) } \\
\text { 2. Blow air for at least } 5 \mathrm{~s} \text {, leaving the surface } \\
\text { glossy. If not, repeat this step. } \\
\text { 3. Light-cure for } 10 \mathrm{~s}\end{array}$ \\
\hline
\end{tabular}

Figure 2- Composition (batch number) and application mode of the materials used in this study 


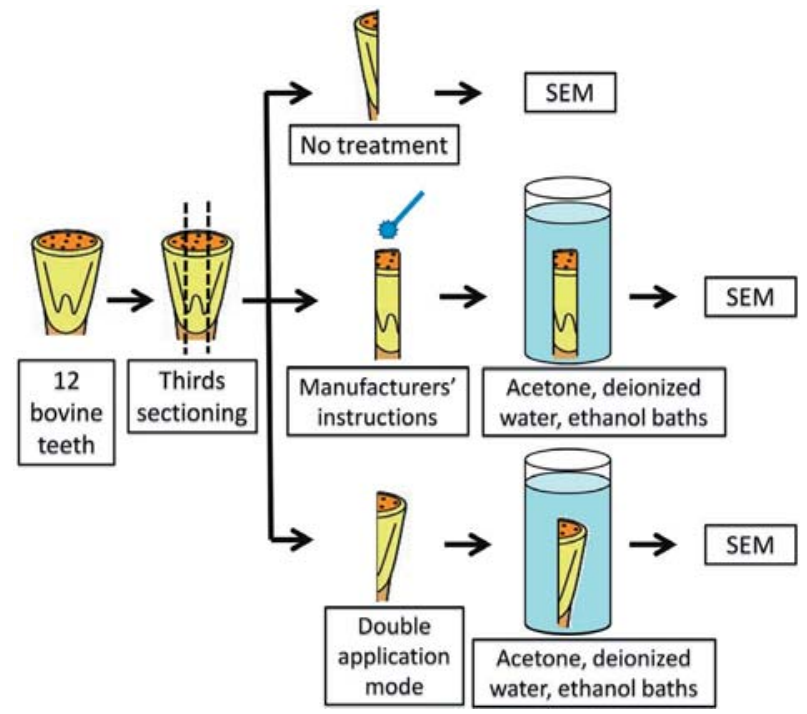

Figure 3- Flowchart of the etching pattern examined by scanning electron microscopy (SEM)

(Material vs. Application time) and Tukey's tests $(\alpha=0.05)$.

\section{RESULTS}

Sclerotic dentin was observed in all specimens used for the $\mu$ TBS testing and, therefore, no specimen was discarded. The two-way ANOVA revealed that the cross-product interaction Adhesive vs. Application time was statistically significant $(p=0.031)$. Under the manufacturers' instructions, the GO adhesive showed the lowest $\mu$ TBS values. The duplication of the application time yielded the highest $\mu$ TBS mean only for the GO adhesive (Tukey's test, $\mathrm{p}<0.05$, Table 1 ). The fracture pattern of the experimental conditions is shown in Table 2. No significant difference was observed between the groups (data not shown).

As for the percentage of the tubule area opening, only the main factor, Application time was significant $(p=0.00003)$. Both treatments (manufacturer's instructions and duplicating the conditioning time) yielded a similar open tubule area $(p=0.89$, Table 3$)$, which were significantly higher than the sclerotic dentin surface (no treatment) (Tukey's test, $\mathrm{p}<0.05)$. Representative

Table 1- Micro-tensile bond strength values (MPa) (means \pm standard deviations) obtained for each experimental condition

\begin{tabular}{ccc}
\hline Adhesive syste & \multicolumn{2}{c}{ Application mode } \\
& Manufacturer's instructions & Double application time \\
\hline Adper Single Bond 2 & $31.1 \pm 3.0^{\mathrm{a}}$ & $30.1 \pm 5.1^{\mathrm{a}}$ \\
\hline Adper Scotchbond SE & $34.0 \pm 5.0^{\mathrm{a}}$ & $31.9 \pm 3.2^{\mathrm{a}}$ \\
GO & $18.4 \pm 7.0^{\mathrm{b}}$ & $30.0 \pm 3.3^{\mathrm{a}}$ \\
\hline
\end{tabular}

Groups with different letters are significantly different $(p<0.05)$. A total of 5 teeth were used per group

Table 2- Number and percentage of specimens (\%) according to fracture pattern mode and the premature de-bonded specimens from each experimental condition $\left(^{*}\right)$

\begin{tabular}{|c|c|c|c|c|c|}
\hline \multirow[t]{2}{*}{ Adhesive } & \multirow{2}{*}{$\begin{array}{l}\text { Application } \\
\text { mode }\end{array}$} & \multicolumn{4}{|c|}{ Fracture pattern } \\
\hline & & $\mathrm{A} / \mathrm{M}$ & CD & CR & D \\
\hline \multirow[t]{2}{*}{$\begin{array}{l}\text { Adper Single } \\
\text { Bond } 2\end{array}$} & $\begin{array}{l}\text { Manufacturer's } \\
\text { instructions }\end{array}$ & $46(82.1)$ & $1(1.8)$ & $4(7.1)$ & $5(8.9)$ \\
\hline & $\begin{array}{l}\text { Double application } \\
\text { time }\end{array}$ & $46(73.0)$ & $6(9.5)$ & $5(7.9)$ & $6(9.5)$ \\
\hline \multirow[t]{2}{*}{$\begin{array}{c}\text { Adper Scotchbond } \\
\text { SE }\end{array}$} & $\begin{array}{l}\text { Manufacturer's } \\
\text { instructions }\end{array}$ & $45(57.7)$ & $17(21.8)$ & $12(15.4)$ & $4(5.1)$ \\
\hline & $\begin{array}{l}\text { Double application } \\
\text { time }\end{array}$ & $38(66.7)$ & $8(14.0)$ & $6(10.5)$ & $5(8.8)$ \\
\hline \multirow[t]{2}{*}{ GO } & $\begin{array}{l}\text { Manufacturer's } \\
\text { instructions }\end{array}$ & $43(81.1)$ & $2(3.8)$ & $4(7.5)$ & $4(7.5)$ \\
\hline & $\begin{array}{l}\text { Double application } \\
\text { time }\end{array}$ & $58(77.3)$ & $4(5.3)$ & $4(5.3)$ & $9(12)$ \\
\hline
\end{tabular}

$\left({ }^{*}\right) \mathrm{A} / \mathrm{M}$ - adhesive/mixed fracture mode; $C D$ - cohesive fracture mode in dentin; $C R$ - cohesive fracture mode in resin; PF - premature failures. 
Table 3- Relative percentage of the tubule area opening (means \pm standard deviations) obtained for each experimental condition $\left({ }^{*}\right)$

\begin{tabular}{cccc}
\hline Material & No treatment & $\begin{array}{c}\text { Application mode } \\
\text { Manufacturer's } \\
\text { instructions }\end{array}$ & Double application time \\
\hline Phosphoric acid & $7.0 \pm 2.5^{\mathrm{a}}$ & $12.4 \pm 4.7^{\mathrm{b}}$ & $12.7^{\mathrm{a}} \pm 4.9^{\mathrm{b}}$ \\
Adper Scotchbond SE & $8.2 \pm 6.7^{\alpha}$ & $14.9 \pm 5.1^{\beta}$ & $18.2 \pm 9.7^{\beta}$ \\
GO & $6.5 \pm 5.0^{\mathrm{A}}$ & $14.8 \pm 5.0^{\mathrm{B}}$ & $12.1 \pm 5.5^{\mathrm{B}}$ \\
\hline
\end{tabular}

$\left({ }^{*}\right)$ Comparation only between lines. Groups with different letters are significantly different $(p<0.05)$. A total of 4 teeth were used per group

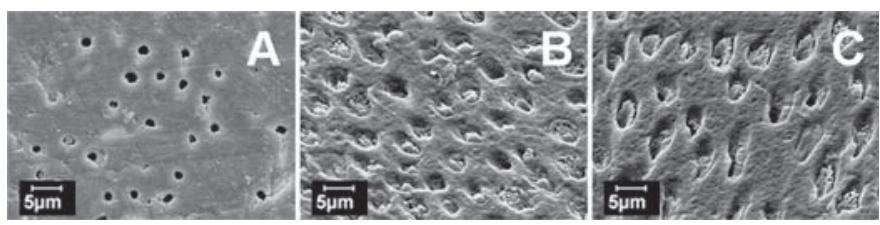

Figure 4- Scanning electron micrographs of sclerotic dentin ( $\mathrm{A}$ - with no treatment) and after phosphoric acid etching (B and $\mathrm{C}$ ). In B: sclerotic dentin treated with phosphoric acid for $15 \mathrm{~s}$ and in $\mathrm{C}$ for $30 \mathrm{~s}$. The number of exposed tubules in $\mathrm{B}$ and $\mathrm{C}$ is higher than $\mathrm{A}$ and similar between them

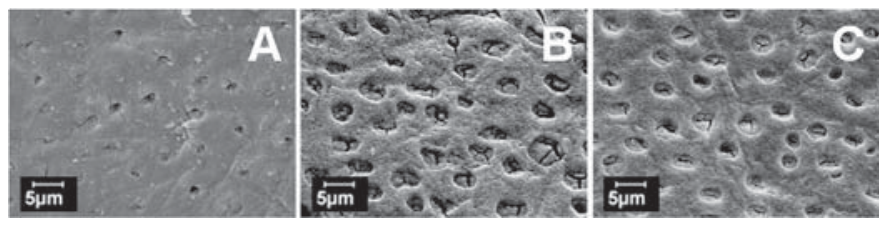

Figure 5- Scanning electron micrographs of sclerotic dentin ( $\mathrm{A}$ - with no treatment) and after application of adhesive system Adper Scotchbond SE (B-C). In B, sclerotic dentin treated for $20 \mathrm{~s}$ and in $\mathrm{C}$, sclerotic dentin treated duplicating the conditioning time. The number of exposed tubules in $B$ and $C$ is higher than $A$ and similar between them

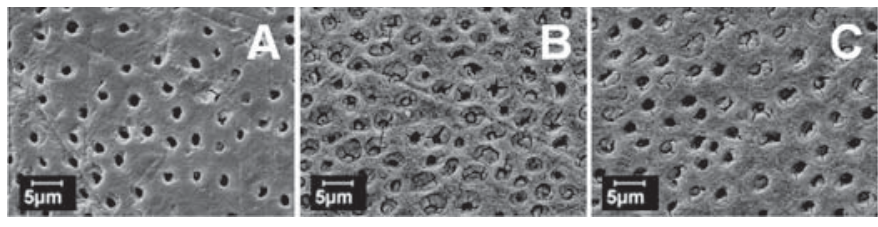

Figure 6- Scanning electron micrographs of sclerotic dentin ( $\mathrm{A}$ - with no treatment) and after application of adhesive system $\mathrm{GO}$ (B-C). In B, sclerotic dentin treated for $20 \mathrm{~s}$ and in $\mathrm{C}$, sclerotic dentin treated for $40 \mathrm{~s}$. Observe that, the number of exposed tubules after conditioning $(B$ and $C$ ) is higher than $A$ and similar between them

images of each experimental condition can be seen in Figures 4 to 6.

\section{DISCUSSION}

Although most in vitro studies that evaluated adhesion to sclerotic dentin used cervical lesions of human dentin as bonding substrates ${ }^{8,19}$, the present study employed bovine sclerotic dentin. This substrate is morphologically similar to human dentin $^{3}$ and, therefore, a suitable substitute for human teeth in bond strength tests ${ }^{24}$. Besides that, bovine specimens are easier to obtain, and the substrate areas for bonding procedures are larger than sclerotic cervical lesions in human teeth ${ }^{28}$.

Sclerotic dentin is a common substrate that occurs in response to tooth wear caused by attrition, abrasion, abfraction or erosion ${ }^{29}$. This substrate has demonstrated to be a challenge for bonding procedures $^{4,7}$. The presence of a hyper-mineralized surface layer, bacteria and sclerotic casts obliterates the dentinal tubules and makes the dentin substrate less susceptible to acid demineralization?.

The results of the present investigation showed that the effect of the experimental treatment on the immediate performance of the adhesive systems is adhesive-dependent, which led us to reject the null hypothesis of this study. The 
duplication of phosphoric acid etching was not capable of increasing the removal of the sclerotic casts presented in the hyper-mineralized surface layer of the sclerotic dentin. The recommended and double etching with $35 \%$ phosphoric acid resulted in a similar open tubule area and $\mu$ TBS values.

Cervical sclerotic dentin, unlike sound dentine, exhibit extensive variations in the hybrid layer thickness within the cervical sclerotic lesions ${ }^{26}$. Using the recommended etching times, the thickness of the hybrid layer may change abruptly due to an uneven etching ${ }^{26}$. This fact may be even worse when the phosphoric acid etching time is duplicated and may account for the controversial results observed when the etching time is duplicated in sclerotic dentin ${ }^{9,26,29}$. Besides that, the duplication of the phosphoric acid etching may cause the deepest demineralization of some intertubular and peritubular dentin, which may not be thoroughly infiltrated by resin monomers ${ }^{10}$.

With regard to the SE adhesives, it has been reported that the additional layers of unpolymerized acidic monomers from SE adhesives may improve their etching potential by increasing the concentration of acidic reagents and counteracting the buffering capacity of hydroxyapatite ${ }^{5}$. The application of a single coat of a SE adhesive (Adper Prompt L-Pop, 3MESPE) was reported to be not enough to make sufficiently thick hybrid and adhesive layers in sound dentin ${ }^{1,22}$. These literature findings led some to hypothesize that the duplication of the SE application could produce a higher dissolution of the sclerotic casts, which was not observed in the present investigation.

Therefore, increased dissolution of sclerotic cast does not explain the increased $\mu$ TBS for the GO adhesive when applied by double the recommended time. Therefore other mechanisms, operating simultaneously, may explain such findings. For instance, it is known that as the solvent is evaporated between each coat, the concentration of co-monomers after each coating increases ${ }^{12}$, thereby improving the quality of the polymer inside the hybrid layer ${ }^{10}$. This was indirectly demonstrated by Nakaoki, et al. ${ }^{21}$ (2005) who observed that the resin that occupied the area of the inter-tubular dentin of fractured dentin surfaces were much denser when the SE adhesive was applied in multiple coatings.

Based on that, one can argue that this technique may be beneficial for adhesive systems that produce weaker polymers. A recent study demonstrated that, among several SE adhesives tested, GO produced the lowest ultimate tensile strength and the lowest $\mu$ TBS values ${ }^{11}$. Earlier studies reported that the ultimate tensile strength of the adhesive systems is positively correlated with the $\mu$ TBS values ${ }^{11,23}$. Therefore, any effort to improve the strength of the adhesive itself may lead to improvements in the resin-dentin $\mu$ TBS of the adhesives.

It is likely that the double application of the GO adhesive may have improved the resin infiltration into the hybrid layer, contributing for the increase in the ultimate tensile strength of the polymer. This led to the achievement of resin-dentin $\mu$ TBS values similar to that obtained for ASE and SB under control and experimental conditions.

Besides that, one cannot rule out the fact that the mode of adhesive application might have played a role in the differences between the GO and ASE. In the present study, the materials were applied according to the manufacturer's instructions, varying only the etching time. The recommended application time of the ASE is higher than the GO (Figure 2). Additionally, the former is recommended to be scrubbed on the surface while the latter is recommended to be only slightly applied. Several recent studies have reported that active application produces the highest immediate and long-term $\mu$ TBS values ${ }^{2,18}$, due to the formation of a polymer with increased cross-linking and greater solvent/ water evaporation.

There are other features of the adhesive ASE that may have accounted for this difference. Contrary to GO, which is a 1 -step self-etch adhesive, ASE is a 2-step self-etch adhesive that takes the additional advantage of having a more hydrophobic and resin filled coating. Thus, even when applied under manufacturer's instructions, the hybridized complex produced by ASE is richer in hydrophobic monomers and fillers making the extra supply of acidic resin by double application useless. The advantages of such hydrophobic resin coating were demonstrated recently by some studies. The application of one coat of a non-solvent containing resin, used to replace the subsequent coat of the hydrophilic adhesives supplied by the manufacturer, was able to increase the $\mu$ TBS of a SE adhesive to sound dentin ${ }^{1,15}$.

Additionally, filled adhesives, such as bottle $B$ from the ASE, produced the thickest adhesive layers, even with a single coat application. Materials similar to ASE produce adhesive layers less sensitive to oxygen inhibition ${ }^{14}$, ensuring adequate coverage of the etched dentin and reducing the harmful effects of oxygen inhibition ${ }^{1,12,22}$.

\section{CONCLUSIONS}

The efficacy of duplicating the conditioning time was only effective for the 1 -step self-etch adhesive system tested. 


\section{REFERENCES}

1- Albuquerque M, Pegoraro M, Mattei G, Reis A, Loguercio AD. Effect of double-application or the application of a hydrophobic layer for improved efficacy of one-step self-etch systems in enamel and dentin. Oper Dent. 2008;33:564-70.

2- Amaral RC, Stanislawczuk R, Zander-Grande C, Gagler D, Reis $A$, Loguercio AD. Bond strength and quality of the hybrid layer of one-step self-etch adhesives applied with agitation on dentin. Oper Dent. 2010;35:211-9.

3- Camargo MA, Marques MM, Cara AA. Morphological analysis of human and bovine dentine by scanning electron microscope investigation. Arch Oral Biol. 2008;53:105-8.

4- Camargo MA, Roda MI, Marques MM, Cara AA. Micro-tensile bond strength to bovine sclerotic dentine: influence of surface treatment. J Dent. 2008;36:922-7.

5- Camps J, Pashley DH. Buffering action of human dentin in vitro. J Adhes Dent. 2000;2:39-50.

6- De Munck J, Van Landuyt K, Peumans M, Poitevin A, Lambrechts $P$, Braem $M$, et al. A critical review of the durability of adhesion to tooth tissue: methods and results. J Dent Res. 2005;84:118-32. 7- El-din AK, Miller BH, Griggs JA. Resin bonding to sclerotic, noncarious, cervical lesions. Quintessence Int. 2004;35:529-40. 8- Eliguzeloglu E, Omurlu H, Eskitascioglu G, Belli S. Effect of surface treatments and different adhesives on the hybrid layer thickness of non-carious cervical lesions. Oper Dent. 2008;33:33845.

9- Georgescu A, Iovan G, Stoleriu S, Topoliceanu C, Andrian S. Atomic force microscopy study regarding the influence of etching on affected and sclerotic dentine. Rom J Morphol Embryol. 2010;51:299-302.

10- Hashimoto M, De Munck J, Ito S, Sano H, Kaga M, Oguchi H, et al. In vitro effect of nanoleakage expression on resin-dentin bond strengths analyzed by microtensile bond test, SEM/EDX and TEM. Biomaterials. 2004;25:5565-74.

11- Hass V, Folkuenig MS, Reis A, Loguercio AD. Influence of adhesive properties on resin-dentin bond strength of one-step self-etching adhesives. J Adhes Dent. 2011;13:417-24.

12- Ito S, Tay FR, Hashimoto M, Yoshiyama M, Saito T, Brackett WW, et al. Effects of multiple coatings of two all-in-one adhesives on dentin bonding. J Adhes Dent. 2005;7:133-41.

13- Kenshima S, Francci C, Reis A, Loguercio AD, Filho LE. Conditioning effect on dentin, resin tags and hybrid layer of different acidity self-etch adhesives applied to thick and thin smear layer. J Dent. 2006;34:775-83.

14- Kim JS, Choi $\mathrm{YH}$, Cho $\mathrm{BH}$, Son $\mathrm{HH}$, Lee IB, Um CM, et al. Effect of light-cure time of adhesive resin on the thickness of the oxygen-inhibited layer and the microtensile bond strength to dentin. J Biomed Mater Res B Appl Biomater. 2006;78:115-23.
15- King NM, Tay FR, Pashley DH, Hashimoto M, Ito S, Brackett WW, et al. Conversion of one-step to two-step self-etch adhesives for improved efficacy and extended application. Am J Dent. 2005;18:126-34.

16- Koase K, Inoue S, Noda M, Tanaka T, Kawamoto C, Takahashi $A$, et al. Effect of bur-cut dentin on bond strength using two all-in-one and one two-step adhesive systems. J Adhes Dent. 2004;6:97-104.

17- Kwong SM, Cheung GS, Kei LH, Itthagarun A, Smales RJ, Tay FR, et al. Micro-tensile bond strengths to sclerotic dentin using a self-etching and a total-etching technique. Dent Mater. 2002;18:359-69.

18- Loguercio AD, Stanislawczuk R, Mena-Serrano A, Reis A. Effect of 3-year water storage on the performance of one-step self-etch adhesives applied actively on dentine. J Dent. 2011;39:578-87. 19- Lopes GC, Baratieri CM, Baratieri LN, Monteiro S Jr, Cardoso Vieira LC. Bonding to cervical sclerotic dentin: effect of acid etching time. J Adhes Dent. 2004;6:19-23.

20- Lopes GC, Vieira LC, Monteiro S Jr, Caldeira de Andrada MA, Baratieri CM. Dentin bonding: effect of degree of mineralization and acid etching time. Oper Dent. 2003;28:429-39.

21- Nakaoki Y, Sasakawa W, Horiuchi S, Nagano F, Ikeda T, Tanaka $\mathrm{T}$, et al. Effect of double-application of all-in-one adhesives on dentin bonding. J Dent. 2005;33:765-72.

22- Pashley EL, Agee KA, Pashley DH, Tay FR. Effects of one versus two applications of an unfilled, all-in-one adhesive on dentine bonding. J Dent. 2002;30:83-90.

23- Reis A, Albuquerque M, Pegoraro M, Mattei G, Bauer JR, Grande $\mathrm{RH}$, et al. Can the durability of one-step self-etch adhesives be improved by double application or by an extra layer of hydrophobic resin? J Dent. 2008;36:309-15.

24- Reis AF, Giannini M, Kavaguchi A, Soares CJ, Line SR. Comparison of microtensile bond strength to enamel and dentin of human, bovine, and porcine teeth. J Adhes Dent. 2004;6:117-21. 25- Senawongse $P$, Srihanon A, Muangmingsuk A, Harnirattisai C. Effect of dentine smear layer on the performance of self-etching adhesive systems: A micro-tensile bond strength study. J Biomed Mater Res B Appl Biomater. 2010;94:212-21.

26- Tay FR, Pashley DH. Resin bonding to cervical sclerotic dentin: a review. J Dent. 2004;32:173-96.

27- Van Dijken JW. Durability of three simplified adhesive systems in Class V non-carious cervical dentin lesions. Am J Dent. 2004; $17: 27-32$.

28- Wegehaupt F, Gries D, Wiegand A, Attin T. Is bovine dentine an appropriate substitute for human dentine in erosion/abrasion tests? J Oral Rehabil. 2008;35:390-4.

29- Wood I, Jawad Z, Paisley C, Brunton P. Non-carious cervical tooth surface loss: a literature review. J Dent. 2008;36:759-66. 